\title{
THE EFFECT OF DEPRIVATION ON PRE-PRESCHOOL COMMUNICATION SKILLS AND PSYCHOLOGICAL DEVELOPMENT
}

\section{Guzal Yakubova}

Tashkent state pedagogical university named after Nizami

\begin{abstract}
The article describes the results of a study conducted to study the impact of communicative communication on the development of the child's mental and cognitive sphere in preschool children in different organizations. At the same time, the level of communicative communication between the child caregiver and the foster child is emphasized as an important role in mental development.
\end{abstract}

Keywords: preschool, mental development, communication, emotional, communicative communication, need, cognitive sphere, personal characteristics, attitude, communication, "I" concept.

Article Received: 18 October 2020, Revised: 3 November 2020, Accepted: 24 December 2020

Emotional communication with adults, an environment rich in stimuli, satisfaction of needs, the ability to exercise, emotional well-being are the main factors in the full and healthy formation of a child's personality. Unsatisfied needs lead to deprivation. Deprivation, in terms of its intensity and duration, in many cases has an irreversible negative impact on the mental development of the child, leading to the cessation of his mental and intellectual development, paving the way for future social interactions with others [1].

From a psychological point of view, communication with adults is a key condition for the mental development of the child, the formation of emotional relationships with others. Its deficiency forms the basis of developmental disorders of foster children in closed orphanages. Children raised in a full-fledged family are better separated from adults by 3 months of age and use more different means of communication than their foster peers in a foster home. A number of studies show that children from foster care show much lower activity in communicative situations.

Positive emotional interactions with the people around him are very important in the mental development and personal formation of a child. This is especially necessary in the first half of a child's life, when it is during this time that his or her relationship with adults becomes directly emotional. This attitude is also considered emotional because the child shows his feelings to the adult and accepts the emotional response of the adult as well. This communication is also called direct communication between the child and the adult because it is indirect and pure [2].

Emotional communication is the primary mental connection between the adult being raised and the child. It is formed in the first months of a child's life and then creates the necessary conditions for communication with adults for various reasons. In addition, when a child engages in emotional communication with adults, he or she also pays attention to sound characteristics and intonation of speech [3].

The concept of "emotional connection" has been commented on in the psychological literature. According to A.V. Zaporozhets, emotional communication is seen as a form of communication, a means of communication and a system of relationships between adults and children. SV Kornitskaya says that emotional communication occurs only when a child accepts the feelings of the person in front of him. Emotional communication is also understood as affective and emotional connections. It is necessary to study them in comparison with other relationships formed with the people around the child [4]. 
As a child interacts with different adults (acquaintances, loved ones, and strangers), different relationships are formed with them: from active and positive, to negative, indifferent, passive. Speech formation and development in children are different. In the literature on speech development problems, speech is divided into active and passive types (A. Aksarina, P. Kaverina, Rosengart-Pupko, TonkovaYampolskaya, T. Tikheeva, etc.). leads to what is said between objects, moves with objects, but it must be understood that he does not speak on his own initiative. Active speech, on the other hand, involves children speaking independently in the process of communicating with the people around them.

The notion of a relationship arises only when it is its object and subject. As a result of the child's interaction with an adult, the image of an adult appears in him and an image of him is formed. Depending on this, the child will have a certain attitude towards adults [5].

Many external and internal conditions and causes affect the transition to active speech. Because these conditions are interrelated. External conditions include emotional communication, emotional connections, cooperation, the ability to accept the terms of communication by the child. Later, in the process of communicating with adults, children gain direct personal experience both in the context of communication and in the context of primary manipulation of objects. This is the basis for the internal development of the child. The child develops an image of the object and the experience of interaction with it. The adult offers the child an object, tells him the name and what to do, and the child develops a connection between the object he sees and the word he hears. The image of hearing develops on the basis of a specific object and the action associated with it. It can be assumed that during this period the child can understand what the adult is saying [6].

Due to the lack of dialogue with an adult close to them or the inadequacy of such a form of communication, children in a closed institution, ie an orphanage, have mental disorders, defects in the ability to understand and communicate with other people [7]. Impairment of communication functions distorts the image of others and the child about himself. The image of others is formed in the child's imagination by understanding and accepting the nonverbal behaviors of adults, through the child's nonverbal interaction with the mother. Since this is a cognitive structure, their formation is subject to social experience [8]. A positive, open, flexible "I" concept plays an important role in building and developing subjective relationships. The root of the object relationship with others is primarily an inadequate attitude towards oneself, inability to accept oneself, lack of self-confidence [9].

Children who are deprived of parental affection when choosing a partner for communication sometimes choose a partner based on a partnership within the framework of interaction (according to which partner choice is five times less common than children raised in a family). Because the opinions of foster children about their peers are full of aggression and anxiety (Davis, 1993). However, T.I. According to Komissarenko's research, an adult's attitude toward a child may affect the nature of his or her interactions with other children.

In this context, given the strong need for communication in the preschool age, we found it necessary to examine the levels of mutual communicative distance between educators and foster children in different institutions as part of our study. In this case, as mentioned above, we used the method of Yu.Ya. Rijonkin "Communicative distance". In the methodology, the evaluation of the test mutual liking is achieved by drawing a straight line between the points on the pole, from the point where the pronoun "I" is expressed to the point where the second person is expressed. In the second stage, the opposite point is represented by the pronoun "I". The full content of the methodology and its stimulus material are given in the appendix. 
Following the implementation of Yu.Ya. Rijonkin's method "Communicative distance", the initial general results are shown in the table below.

\section{$1^{\text {st }}$ table}

Comparative analysis of communicative distance indicators in different institutions

\begin{tabular}{|c|c|c|c|c|c|c|}
\hline Institutions surveyed & & & & & & \\
& $\mathbf{N}$ & $\mathbf{x}$ & $\boldsymbol{\sigma}$ & $\mathbf{m}$ & $\mathbf{t}$ & $\mathbf{p}$ \\
\hline $\begin{array}{l}\text { Preschool education } \\
\text { institutions }\end{array}$ & 31 & 0.51 & 0.14 & 0.02 & \multirow{2}{*}{5.3} & 0,001 \\
\cline { 1 - 4 } Orphans' home & 30 & 0.28 & 0.2 & 0.03 & \multirow{2}{*}{4.3} & 0,001 \\
\hline Towns of children & 28 & 0.35 & 0.14 & 0.02 & 4.3 \\
\hline
\end{tabular}

The method of studying the communicative gap in preschool children in different institutions, described in the table above, can be analyzed as follows, ie in the method of determining the communicative gap in preschoolers the arithmetic mean is 0.51 , the mean square spread is 0.14 , the average error is 0.02 . equal, developed a reliable communication between them, which has a positive effect on the mental development of the child. The average arithmetic value of the orphanage was 0.28 , the mean square deviation was 0.2 , and the average error was 0.03 , in which these indicators show a negative and formal relationship with the educator in the orphanage. This, in turn, has a negative psychological effect on the formation of the child's personality. There is a significant difference between preschoolers and children living in orphanages $(\mathrm{t}=5.34 ; \mathrm{p}$ $<0.001)$. In our opinion, the main reason for this is that orphanage educators engage in very formal and negative interactions with children deprived of parental care.

Satisfaction of the need to communicate with adults and the world of objects can be somewhat compensated for by the interactions of children in the orphanage with their peers. It is known that constant and emotional communication with adults helps children to form interactions with each other much earlier. Babies in foster care, on the other hand, choose their peers differently, striving for active, mobile, and emotional children [11].

According to MM Tsaregorodtseva, the peer next to the child can not influence his development and can not fill the relationship with content. These children prefer to observe their peers, have less active relationships with their partner, their facial expressions are poorer, so an adult will need to direct the children's relationships, teaching others to see the same person as themselves. Children's interactions increase their emotional tone and gift new impressions, which is very important for an indoor institution like an orphanage. Children's interactions affect their overall mental development. They serve as an important source in the development of the child's cognitive activity. The main direction in the mental development of the child is his interaction with adults. Due to the late development of the need for this communication in the orphanage, the child does not have full emotional-personal communication, the need for situational-business cooperation with adults is not formed in time, it is left behind. In addition, foster children do not have a subjective-personal, focused relationship with adults as children growing up in a family [12].

The arithmetic mean of the indicators in the Children's Town (SOS) inmates was 0.35, the mean square root scatter was 0.14 , and the mean 
error was 0.02. Such indicators mean that children interact formally with the caregiver on the campus in their main activities, but how emotionally rich the communication is plays an important role in a child's mental and emotional development.

The difference between preschoolers and children living in children's camps (SOS) is $(\mathrm{t}=$ 4.3; $\mathrm{p}=0.001)$. That is, the communicative distance indicators are somewhat better between the caregiver and the child than those in the foster care home. One of the main reasons for this is the creation of conditions close to the family environment in SOS. Since children of different ages are brought up in each house of the orphanage, and the main task of their caregivers is to try to play the role of mother, this is the main reason why the orphanage differs slightly from that of the orphanage. we think. Thus, research has shown that the main activity between a child and a caregiver is negative and formal communication due to certain conditions in foster children. We present the following diagram to give a more accurate picture of the results obtained.

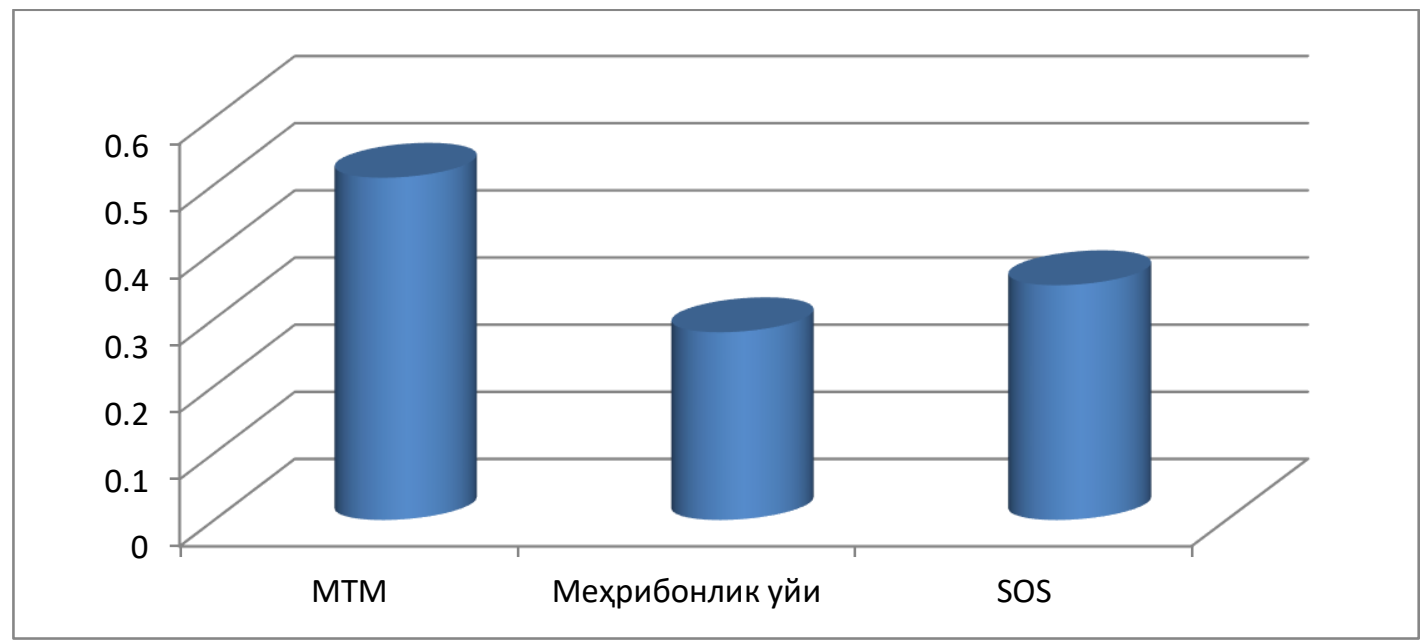

Figure 1. Indicators of communicative distance of preschool children in different educational institutions

As a continuation of the research, we tried to determine the level of interest in the communication of information from the "I" to the communication partner as an object of communication using the method of "Communicative distance" by Yu.Ya.

Table 2

Communicative intermediate attitude of the child to the educator in different institutions

\begin{tabular}{|c|c|c|c|c|c|c|}
\hline Institutions surveyed & & & & & & \\
\hline $\begin{array}{c}\text { Preschool education } \\
\text { institutions/ orphans' } \\
\text { home }\end{array}$ & $64 / 62$ & $0,5 / 0,3$ & $0,15 / 0,19$ & $0,01 / 0,02$ & -6.5 & 0,001 \\
\hline $\begin{array}{c}\text { Orphans' home/ town of } \\
\text { children }\end{array}$ & $62 / 53$ & $0,3 / 0,39$ & $0.19 / .15$ & $0,02 / 0,02$ & -2.6 & 0,008 \\
\hline
\end{tabular}




\begin{tabular}{|c|c|c|c|c|c|c|c|}
\hline $\begin{array}{l}\text { Orphans' home/ town of } \\
\text { children }\end{array}$ & $64 / 53$ & $0.5 / 0.39$ & $0.15 / .15$ & $0,01 / 0,02$ & -4.0 & 0,001 \\
\hline $\begin{array}{c}\text { Institutions } \\
\text { surveyed }\end{array}$ & $\mathbf{N}$ & $\mathbf{X}$ & $\mathbf{\sigma}$ & $\mathbf{m}$ & $\mathbf{t}$ & $\mathbf{p}$ \\
\hline $\begin{array}{c}\text { Preschool } \\
\text { education } \\
\text { institutions/ } \\
\text { orphans' home }\end{array}$ & $64 / 62$ & $0.43 / 0.21$ & $0.16 / 0.21$ & $0.02 / 0,02$ & -5.4 & 0.001 \\
\hline $\begin{array}{c}\text { Orphans' } \\
\text { home/ town of } \\
\text { children }\end{array}$ & $62 / 53$ & $0.21 / 0.24$ & $0.21 / 0.15$ & $0,02 / 0,02$ & 0.692 & 490 \\
\hline $\begin{array}{c}\text { Orphans' } \\
\text { home/ town of } \\
\text { children }\end{array}$ & $64 / 53$ & $0.43 / 0.24$ & $0.16 / 0.15$ & $0.02 / 0.02$ & -7.1 & 0.001 \\
\hline
\end{tabular}

The method of studying the communicative gap of preschool children in different institutions, as shown in the table, can be analyzed as follows: the arithmetic mean of the level of interest of preschool children in relation to the educator is 0.5 , the mean square spread is 0.15 , the average error is 0.01 . , they developed a formal, positive dialogue between the child and the caregiver on the Rijonkin scale.

The arithmetic mean of the children in the orphanage was 0.3 , the mean square spread was 0.19 , and the mean error was 0.02 , indicating that these figures correspond to the negative, formal scale of this methodology. In the orphanage, the communicative interaction with the educator shows a negative and formal relationship. There are significant differences between preschoolers and children living in orphanages $(\mathrm{t}=-6.5 ; \mathrm{p}$ $<0.001)$.

The arithmetic mean of the children living in the children's camp (SOS) is 0.39, the mean square scatter is 0.15 , and the mean error is 0.02 , which corresponds to the official scale of the methodology used. The main activities of mothers and children are formal communication.

The difference between the children of the preschool and the children living in the children's camp (SOS) $(\mathrm{t}=4.3 ; \mathrm{p}=$, 001) is slightly better than the communicative distance between the foster child and the foster child. It is worth noting the comments of N.A. Menchinskaya and V.S. Mukhina, who believe that the main factor of whims in children is the unfair, wrong, disrespectful attitude of adults around them and extinguish the child's curiosity [13].

No significant differences were identified between the children left without parental care in the orphanage and the inmates living in the SOS campus, as described in the table above.

The diagram below shows a clear picture of the results. 


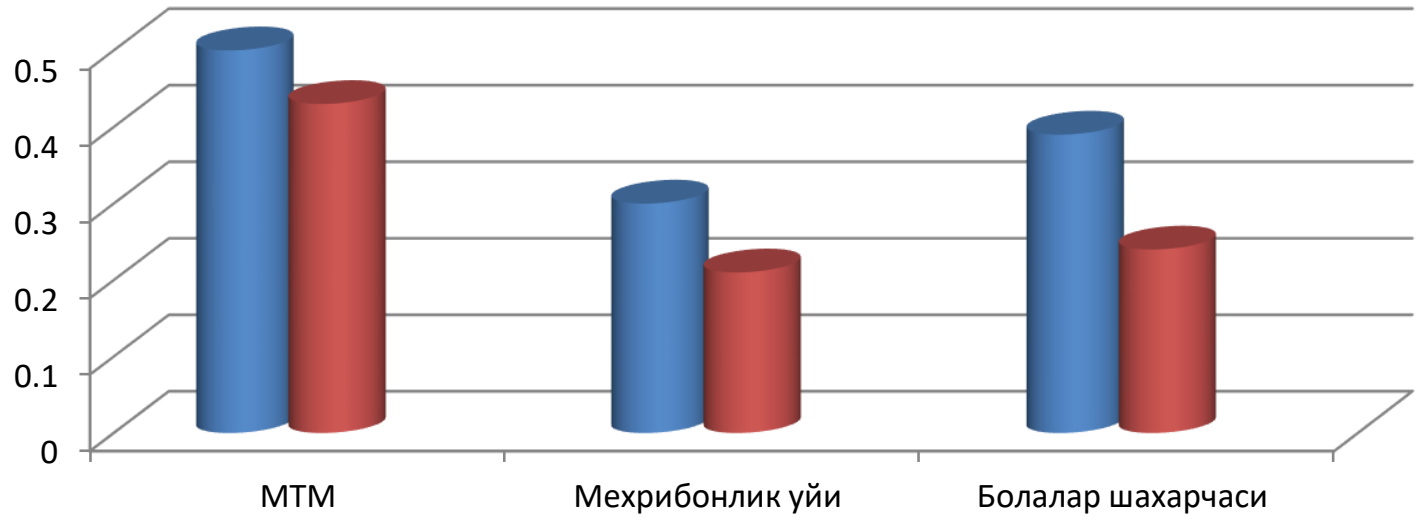

Figure 2. Indicators of communicative distance of preschool children in different educational institutions

In the second stage of the methodology conducted in the psychodiagnostic activity of the study, we tried to analyze the process from the second person close to the subject to the pronoun "I".

Table 3 Comparative presentation of "Communicative distance" in different institutions (educator's communicative intermediate attitude to the child)

The level of interest of preschool educators in the child's personality and the arithmetic mean of the communicative distance is 0.43 , the mean square spread is 0.16 , the average error is 0.02 , according to Yu. Rijonkin's scale formal communication is advanced, but this level of communication cannot be said to be positive. The arithmetic mean of the orphanage educator's interest in the child's personality, the level of communicative spacing and the relationship is 0.21 , the mean square spread is 0.21 , and the mean error is 0.02 , in which these indicators correspond to the required scale of this method. can be seen. This means that communicative communication with the educator is a necessary and obligatory relationship in the orphanage. There are significant differences between preschoolers and children living in orphanages $(\mathrm{t}$ $=-5.4 ; \mathrm{p}<0.001)$. The importance of emotional communication for a child's mental development, and especially speech development, can also be evidenced by speech defects and backwardness in children in deprivation. Lack of emotional communication causes the child to lag behind in all mental development, speech and knowledge acquisition [14].

Intermediate indicators of interest and communicative communication of mothers living in children's camps (SOS) with children have an arithmetic mean of 0.24 , a mean square of 0.15 and an error of 0.02 , which corresponds to the official scale of the methodology. , it can be seen that the main activities of the children take place in a formal dialogue with the educator in the children's town, i.e. the foster mothers.

In the difference between preschool children and children living in the SOS camp $(\mathrm{t}=$ $-7.1 ; \mathrm{p}<0.001)$, the communicative distance is slightly better between the educator and the child than in the orphanage, but in the process of communication between preschool teachers and children. it can be seen in the table based on the results of the research that the interest and attitudes are higher than the educators in the other two institutions.

No significant differences were identified between the children left without parental care in the orphanage and the inmates living in the SOS camp, as described in the table above.

The role of communicative communication distance and its impact on cognitive processes in the mental development of preschool children and in the development of all processes in the cognitive sphere can be seen in the table below. 


\begin{tabular}{|c|c|c|c|c|c|c|}
\hline & $\begin{array}{l}\text { Communicati } \\
\text { ve distance }\end{array}$ & $\begin{array}{c}\text { attentio } \\
\mathbf{n}\end{array}$ & $\begin{array}{l}\text { intelle } \\
\text { gence }\end{array}$ & memory & Idea & $\begin{array}{c}\text { Smal } \\
\text { motor } \\
\text { skills }\end{array}$ \\
\hline $\begin{array}{c}\text { Communicati } \\
\text { ve distance }\end{array}$ & 1 & $0,474^{* *}$ & $0,340^{* *}$ & $0,372^{* *}$ & $0,376^{* *}$ & $0,395^{* *}$ \\
\hline attention & & 1 & $0,723^{* *}$ & $0,625^{* *}$ & $0,725^{* *}$ & $0,610^{* *}$ \\
\hline Knowledge & & & 1 &, $495^{* *}$ & $0,673^{* *}$ & $0,503^{* *}$ \\
\hline Memory & & & & 1 & $0,716^{* *}$ & $0,526^{* *}$ \\
\hline Idea & & & & & 1 & $0,560^{* *}$ \\
\hline $\begin{array}{c}\text { Small motor } \\
\text { skills }\end{array}$ & & & & & & 1 \\
\hline
\end{tabular}

Table 4 Indicators of the relationship between the communicative distance and the cognitive sphere

(K. Pearson on the correlation coefficient).

As shown in the table above, a positive link between communicative communication and cognitive processes can be seen in preschool children. How emotionally rich and respectful the child is in the process of communication with the child, which is formed by adults as a person, has a positive effect on the development of his cognitive sphere. If we look at the expressed correlations of attention, cognition, memory, thinking and fine motor skills in the processes of cognition with communicative distances and scales of Yu.A. 0.01). Attention is one of the most important cognitive areas in personality development. Because in the educational process, the importance of voluntary and sustained attention in independent mental work for learning, solving examples and problems, performing exercises, repetition, voluntary effort.

There was a positive correlation between the interaction of adults with children and the closeness of the communicative distance and the development of cognition in the process of communication $(r=0.340 ; p<0.01)$. As the main activity of the child in preschool age is play, the child's ability to perceive time, space and movement in direct contact with peers and adults in play activities, these psychological categories begin to rise to a qualitatively new stage of development. Also, the development of speech activity allows for better comprehension and understanding of the speech of others, further expanding the scope of interpersonal relationships.

One can also see a positive correlation between the levels of communication and one of the cognitive processes, memory formation $(\mathrm{r}=$ $0.340 ; \mathrm{p}<0.01)$. From this it can be understood that emotionally close relationships play an important role in a child's mental development. The attitude of adults to the formation of a child's memory has an impact on the child's later life, for example, from the point of view of the school of 
psychoanalysis, the age of 5-6 years is an important stage in the formation of the child's future personality. Neuroses in a person are associated with associations.

In communication, there is a positive correlation between interaction and thinking $(\mathrm{r}=0.729 ; \mathrm{p}$ <0.01). The most complex process in the cognitive realm is thinking. In the development of thinking, the attitude of the child to the mother or the adults around him, the warmth of the communication process has a significant impact on the age-specific nature of thinking, its development and the formation of concepts.
A positive relationship between the development of fine motor skills and the communication process can also be seen $(r=0.395 ; p<0.01)$. The development of fine motor skills in children is associated with the development of reciprocal speech. The better the fine motor skills are developed, the richer and more fluent the child's speech will be. The development of fine motor skills, in turn, is associated with communication. That is, the more and more close contact a child has with an adult, the better the development of the child's fine motor skills.

Table 5

Indicators of correlation between communicative distance and individual characteristics in preschool children

\begin{tabular}{|c|l|c|c|c|c|}
\hline $\begin{array}{c}\text { Psychological } \\
\text { variables }\end{array}$ & $\begin{array}{l}\text { Method of } \\
\text { studying } \\
\text { communicati } \\
\text { ve } \\
\text { communicati } \\
\text { on }\end{array}$ & $\begin{array}{c}\text { Heterono } \\
\text { m/ Auto } \\
\text { nominalit } \\
\text { y }\end{array}$ & $\begin{array}{c}\text { Concentri } \\
\text { city / } \\
\text { Eccentrici } \\
\text { ty }\end{array}$ & $\begin{array}{c}\text { The } \\
\text { combinatio } \\
\text { n of } \\
\text { personal } \\
\text { characteris } \\
\text { tics }\end{array}$ & $\begin{array}{c}\text { The } \\
\text { autonomic } \\
\text { nervous } \\
\text { system }\end{array}$ \\
\hline $\begin{array}{c}\text { Method of } \\
\text { studying } \\
\text { communicative } \\
\text { communication }\end{array}$ & 1 & $-0,17^{*}$ & $0,19^{* *}$ & 0,097 & $-0,017^{*}$ \\
\hline $\begin{array}{c}\text { Heteronom/ } \\
\text { Auto } \\
\text { nominality }\end{array}$ & 1 & $-0,237^{* *}$ & $-0,02$ & $-0,215^{* *}$ \\
\hline $\begin{array}{c}\text { Concentricity / } \\
\text { Eccentricity }\end{array}$ & & & 1 & $-0,224^{* *}$ & $-0,122$ \\
\hline $\begin{array}{c}\text { Harmony of } \\
\text { personal } \\
\text { characteristics }\end{array}$ & & & & & \\
\hline $\begin{array}{c}\text { Features of the } \\
\text { autonomic } \\
\text { nervous system }\end{array}$ & & & & & \\
\hline
\end{tabular}

From the above correlation coefficients, it is clear that there is a negative relationship between the communicative distance and the heteronomy / autonomy scales $(\mathrm{r}=-0.170 ; \mathrm{p}<0.05)$. This suggests that the closer the distance of communication, the more autonomy develops in the formation of personality. In other words, a person has an opinion and is able to express it in different situations. Autonomy is associated with a high quality of mental state, and autonomy 
encourages an individual to self-assess any situation independently.

There is also a positive correlation between communicative distance and concentration and eccentricity ( $\mathrm{r}=0.19 ; \mathrm{p}<0.01)$. This can be explained by the fact that the emotional richness of communication plays an important role in the formation of eccentricity in the mental development of the individual. A person's interest in the environment, his attitude to the outside world that surrounds him, and his source of help from the outside world in a problematic situation show moderation in his mental state.

Correlation can also be seen with communication distance and features of the autonomic nervous system ( $r=-0.017$; $\mathrm{p}<0.05)$. It can be seen that parasympathetic activity predominates in the features of the autonomic nervous system. When parasympathetic activity predominates in a person, there is a slowing of the pulse, a decrease in blood pressure, narrowing of the pupil, better morning time at work.

Furthermore, in this correlation, a relationship can also be seen between the heteronomy / autonomy scale and the concentricity / eccentricity scale $(r=-0.237 ; p$ <0.01). Hence, in the formation of an autonomous person, eccentricity is also formed. These two mental processes help a person socialize and gain a place in society. However, it can be seen that the heteronomy / autonomy scale is also interrelated with the characteristics of the autonomic nervous system

( $\mathrm{r}=-0.215 ; \mathrm{p}<0.01)$. We included blood pressure, pulse, activity in the autonomic nervous system. At the same time, it should be noted that autonomy can always affect the autonomic nervous system in the development of the individual.

It was found that the concentricity / eccentricity scale of the methodology was also negatively correlated with the individual quality matching scale $(\mathrm{r}=-0.224 ; \mathrm{p}<0.01)$. As eccentricity develops in a person, his personal qualities are balanced and form a whole.
The final indicator of the method is the scale of the combination of personal qualities, as well as a negative relationship with the autonomic nervous system.

$(r=-0,201 ; p<0,01)$. The predominance of sympathetic or parasympathetic (vagotonia) activity is likely to be related to the combination of personality traits.

Based on the results of the conducted psychodiagnostic activity, it can be said that emotional communication and close relationship with the child play a very important role in the formation of the person in his mental development. Formal, compulsive, and negative attitudes toward the child are considered to be the main factors causing disturbances in mental development. Satisfaction of a child's need for communication with adults is interrelated with the development of his cognitive sphere and personal characteristics. If the child feels good in communication with adults and has the opportunity to express himself, in the future the child's self-confidence and self-esteem will be positively formed.

\section{Conclusion}

we can analyze our observations in different educational institutions, that is, the agenda in orphanages and the activities of foster children, which allowed us to see a number of problematic situations in children, such as aggressive response, frequent conflicts, fear, anxiety, lack of confidence in relationships and behavioral deviations. The problem is that the caregivers of the orphanage do not know how to behave in such situations in the behavior of the children and make some mistakes in dealing with the child in order not to increase the problem situation. Ignoring specific features in a child's mental development does not take into account the child's emotional state when engaging in communication, and it is precisely the levels of communication that cause the child to become anxious. 


\section{REFERENCES}

[1] Antonova T.V. The meaning of communication methods in the game for the regulation of children's relationships // Activities and relationships of preschoolers / ed. Т.а. Репиной. М.: Pedagogy, 1987. P. 71-108

[2] Arxireva T.V. Features of the experience of emotions by children-pupils of a children's shelter / T.V. Arhireeva, T.N. Stabachina // Social work with children and adolescents of the risk group $\mathrm{SPb}$., 2000 - pp. 21-22

[3] Boulby - M.: Gardariki, 2003. 241c

[4] Grochkrosh K. Schmidt W. Nymann, I., to the question of adaptation when moving children from a nursery to kindergarten. M.: Pediatrics, 1979, 3, 16-17.

[5] Dubrovina, I.V. Features of the mental development of children in the family and outside the family / I.V. Dubrovina, M.I. Lisin // age features of the mental development of children: Sat. scientific. Proc. M, 1982. - 164C.

[6] Elagina MG, Guskova T.V. Development of the child's personality in critical periods of childhood // Development of the child's psyche in communication with adults and peers: Sat. scientific. Proc. / Ed. А.г. Рузской. M, 1990. Р. 32-38.

[7] Komissarenka T.I. The influence of communication of children with adults on the formation of types of relationships of children with peers // New research in psychology. 1977. No. 1 (16). P. 45-48.

[8] Lebedov V.I. Personality in extreme conditions. M., 1989.

[9] Lisina M.I. Genesis forms of communication in children // The principle of development in psychology / ed. M.: Nauka, 1978. P. 268-294

[10] Lisina M.I., Kapchal G.I. Communication with adults and psychological training of children to school / ed. A.I Silvester. Chisinau: STITZA, 1987. 135 p.

[11] Zaporej A.V. The value of the early periods of childhood for the formation of a childhood personality. // Principle of development in psychology. - M.: Knowledge, 1978.- 267C

[12] Ranshburg, Popper P. Personal Secrets. M., 1983

[13] Draining the speech of children of preschool age: manual for the teacher of children. the garden. / Ed.F.A.Soxina. 2nd ed., Act. - M.: Enlightenment, 1979. $223 \mathrm{p}$.

[14] Ryumshina L.I. Psychological features of the knowledge of other people with children raising in the family and in the orphanage: Dis.Kand. Psychol.Nuk. M. 1990. 155 p.

[15] Ruzskaya A.G. Features of communication of children 2-7 years old with outsiders and close adults // Communication and its influence on the development of the psyche of the preschooler. M.: 1974. P. 41-58

[16] Semia G.V. Basics of social psychological protection of graduates of educational institutions for children orphans and children left without parental care. - M., 2001. 115C. 